\title{
Multi-drugs resistant acne rosacea in a child affected by Ataxia-Telangiectasia: successful treatment with Isotretinoin
}

\author{
Nicoletta Cantarutti ${ }^{*}$, Alessia Claps ${ }^{1}$, Giulia Angelino ${ }^{1}$, Luciana Chessa ${ }^{2}$, Francesco Callea ${ }^{3}$, May El Hachem ${ }^{4}$
} Andrea Diociaiuti ${ }^{4}$ and Andrea Finocchi ${ }^{1}$

\begin{abstract}
Ataxia-Telangiectasia is a rare multisystem autosomal recessive disorder [OMIM 208900], caused by mutations in Ataxia-Telangiectasia Mutated gene. It is characterized by neurological, immunological and cutaneous involvement. Granulomas have been previously reported in Ataxia-Telangiectasia patients, even if acne rosacea has not been described. We report a case of a young Ataxia-Telangiectasia patient with a severe immunological and neurological involvement, who developed granulomatous skin lesions diagnosed by skin biopsy as acne rosacea. Considering the severe clinical picture and the lack of improvement to multiple topic and systemic therapies, treatment with Isotretinoin was started and the skin lesions disappeared after five months. However the therapy was stopped due to drug-hepatotoxicity. Systemic treatment with Isotretinoin should be carefully considered in patient with Ataxia-Telangiectasia for the treatment of multi-drug resistant acne rosacea, however its toxicity may limit long-term use and the risk/benefit ratio of the treatment should be evaluated.
\end{abstract}

Keywords: Ataxia-telangiectasia, Acne rosacea, Granulomas, Isotretinoin

\section{Background}

Ataxia-Telangiectasia (A-T) [OMIM 208900] is a rare multisystem autosomal recessive disorder, caused by mutations in ATM (Ataxia-Telangiectasia Mutated) gene. It is characterized by cerebellar ataxia, oculocutaneous telangiectasias, oculomotor apraxia, variable immunodeficiency with recurrent infections, radiosensitivity and predisposition to malignancies. Cutaneous involvement usually includes telangiectasia, cafè-au-lait macules, hyper and hypopigmented macules and progeroid changes. Eczema and acanthosis nigricans may also be present, as well as vitiligo and granulomas [1].

Diagnosis is suggested by the clinical aspects, in according with elevated serum levels of alfa-fetoprotein and confirmed by detection of ATM protein expression by western blot analysis and identification of the gene mutations.

\footnotetext{
* Correspondence: nicolcant@hotmail.it

'Department of Systems Medicine, University of Rome "Tor Vergata", Unit of Immunology and Infectious Disease, "Bambino Gesù" Children's Hospital, Via Montpellier 1, 00133 Rome, Italy

Full list of author information is available at the end of the article
}

Cutaneous granulomatosis with unknown etiology, not related to infections, occur rarely in patients with primary immunodeficiencies (PIDs) [2]. These granulomas have been previously described in CVID, CGD, SCID, X- hypogammaglobulinemia, Wiskott-Aldrich syndrome and in A-T $[2,3]$. Particularly acne rosacea has not been described before in patients with A-T. We report a case of multidrugs resistant acne rosacea in ataxia-telangiectasia, successful treated with Isotretinoin.

\section{Case report}

A 15 years old girl, born from healthy Caucasian nonconsanguineous parents, referred to our center at the age of 2 years with a history of failure to thrive and ataxic gate. The neurological picture was characterized by trunk and head ataxia, oculomotor apraxia, hypotonus, dysarthria, dysmetria and intention tremor. Physical examination revealed oculocutaneous telangiectasias, cafè-au-lait macules and striae rubrae. She suffered from recurrent infections, particularly by respiratory tracts infections and repeated episodes of fever of unknown origin. During follow up she developed chronic EBV infection that lead to 
arthritis EBV-related, requiring treatment with Rituximab at a weekly dose of $375 \mathrm{mg} / \mathrm{m} 2$ for 2 weeks. Immunological studies reveled a combined immunodeficiency, characterized by low level of serum IgA; non protective specific antibodies response against tetanus, after vaccination; $\mathrm{T}$ and $\mathrm{B}$ lymphopenia, associated with reduced naïve

Table 1 Immunological data of the patients showing decrease level of $\operatorname{IgA}, T$ and $B$ lymphopenia; reduced naïve T subsets (CD4RA,CD8RA); low lymphocyte proliferation to $\mathrm{PHA}$; nonprotective specific antibodies response against tetanus, after vaccination; skewed T Cell Receptor repertoire

\begin{tabular}{|c|c|c|}
\hline \multicolumn{2}{|c|}{$\mathrm{WBC} / \mathrm{ml}$} & 9080 \\
\hline \multicolumn{3}{|c|}{ Serum immunoglobulin mg/dl } \\
\hline \multicolumn{2}{|l|}{$\lg A$} & $<5$ \\
\hline \multicolumn{2}{|l|}{$\lg M$} & 187 \\
\hline \multicolumn{2}{|l|}{$\lg G$} & 1158 \\
\hline \multicolumn{2}{|l|}{$\lg G 1$} & 906 \\
\hline \multicolumn{2}{|l|}{$\lg G 2$} & 94.3 \\
\hline \multicolumn{2}{|l|}{$\lg G 3$} & $10: 01$ \\
\hline \multicolumn{2}{|l|}{$\operatorname{lgG4}$} & 7.16 \\
\hline \multicolumn{3}{|c|}{$\begin{array}{l}\text { Lymphocyte phenotype } \\
\text { (percentage and absolute number) }\end{array}$} \\
\hline \multicolumn{2}{|l|}{ Absolute count/ml } & 1260 \\
\hline CD3 & $33 \%$ & 534.6 \\
\hline CD4 & $18 \%$ & 291.6 \\
\hline CD4RA & $1.6 \%$ & 25.9 \\
\hline CD4RO & $15.5 \%$ & 251.1 \\
\hline CD8 & $11 \%$ & 178.2 \\
\hline CD8RA & $5.6 \%$ & 90.7 \\
\hline CD8RO & $5.2 \%$ & 84.2 \\
\hline CD19 & $6 \%$ & 97.2 \\
\hline CD16-56 & $50 \%$ & 810 \\
\hline \multicolumn{3}{|c|}{ Response to mitogens (counts per min) } \\
\hline \multicolumn{2}{|l|}{$\mathrm{PHA}$} & $19 \%$ \\
\hline \multicolumn{2}{|l|}{ OKT3 } & $48 \%$ \\
\hline \multicolumn{3}{|l|}{ Response to vaccination } \\
\hline \multicolumn{2}{|l|}{ Ab anti-Tet } & $0.1 \mathrm{U} / \mathrm{ml}$ \\
\hline \multicolumn{2}{|l|}{$A b$ anti-PCP } & $50 \mathrm{mg} / \mathrm{l}$ \\
\hline \multicolumn{2}{|l|}{$\mathrm{Ab}$ anti-HiB } & $0.3 \mathrm{mg} / \mathrm{l}$ \\
\hline \multicolumn{3}{|l|}{ Phenotype B } \\
\hline \multicolumn{2}{|l|}{$\mathrm{CD} 22+\mathrm{CD} 27+\lg \mathrm{D}+\lg \mathrm{M}+$} & $7.2 \%$ \\
\hline \multicolumn{2}{|l|}{ CD22+CD27+lgD-lgM- } & $20.2 \%$ \\
\hline \multicolumn{2}{|l|}{ CD22+CD27-lgD+lgM+ } & $60.5 \%$ \\
\hline CD21lowCD38NEG & & $28.7 \%$ \\
\hline CD4+ and CD8+ TCR ana & & \\
\hline CD4+ SKEWED & & $43 \%$ \\
\hline CD8+ SKEWED & & $100 \%$ \\
\hline
\end{tabular}

T subsets; low lymphocyte proliferation to PHA and skewed T Cell Receptor repertoire (Table 1). On the basis of the infections history and immunological assessment, intravenous immunoglobulin replacement therapy (IVIG) was started. Diagnosis of Ataxia-Telangiectasia (A-T) was confirmed by molecular analysis of ATM gene and by the evidence of ATM protein absence by western blot analysis.

At the age of 10 years the girl developed papules, pustules and granulomatous skin lesions with centrofacial distribution; a diagnosis of herpetic infection in immunocompromised patient has been suggested due to the presence of vesicular-pustular lesions with central umbilication. Treatment with acyclovir was started, in addition to systemic and local antibiotic therapy, but no improvement was observed. Because of the persistence and spreading of cutaneous lesions (Figure 1) and the negative result of DNA-HSV on the peripheral blood, a skin biopsy was performed and the histological study revealed a granulomatous inflammatory process rich in epithelioid histiocytes with a few multinucleated giant cells (Figure 2a-d). Stains for pathogens (Ziehl-Neelsen, PAS, Giemsa) were negative. The diagnosis of granulomatous acne rosacea was made. Rosacea fulminans was excluded because of the long lasting course characterized by a slow formation of new cutaneous lesions without draining sinuses. Moreover, on histology granulomas were striking while papillary dermis edema and deep dermal fibrosis were minimal. Therefore, the patient underwent oral and topical metronidazole treatment, but a significant worsening of the skin lesions with bacterial superinfection rapidly followed a slight improvement. Topical clindamycin was added to the ongoing therapy, while metronidazole was stopped due to detection of hypertransaminasemia at the blood tests. An assay with topical Pimecrolimus and systemic and topical Tetracycline was attempted, but, after a short period of improvement, a new worsening of the skin lesions occurred.

Considering the severe clinical picture and the lack of improvement to multiple therapies, systemic treatment with Isotretinoin $(0,5 \mathrm{mg} / \mathrm{kg} / \mathrm{die})$ was started. The lesions

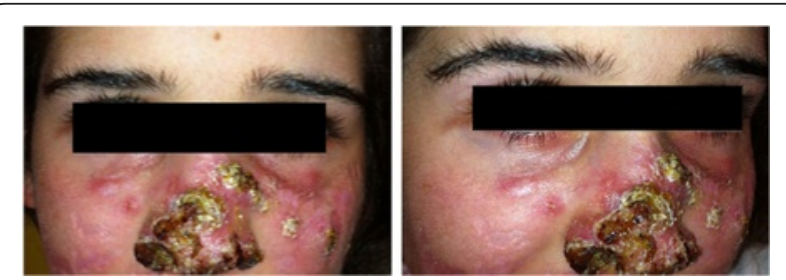

Figure 1 Picture of the patient showing the presence of erythematous, papular-nodular lesions and telangiectasias on the face; ulceronecrotic lesions on the nasal pyramid with destructive effect on the wings of the nose. Some scars are evident as result of the disease. 


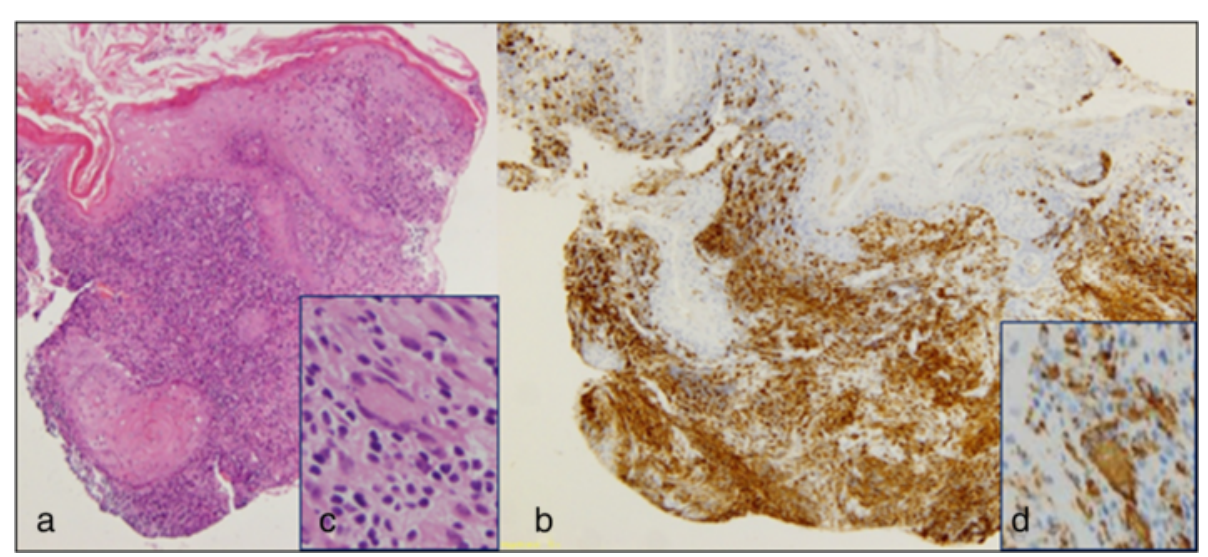

Figure 2 Histological images of skin biopsy revealing a granulomatous inflammatory process. The microphotograph shows a severely damaged epidermis due to a dense inflammatory process obliterating the entire dermis, mainly composed of histiocytes with an epithelioid appearance and lymphocytes arranged in a granulomatous pattern (a). The immunostaining for CD68 shows positivity in the vast majotity of infiltrating cells (b). A few multinucleated giant cell of Langhans type are present (c, insert) which are positive for CD 68 (d), insert). a) HE 10 x; b) Immunostaining $20 \mathrm{x}$; c) HE $40 \mathrm{x}$; d) Immunostaining $40 \mathrm{x}$.

showed mild improvement after four weeks and almost disappeared after five months (Figure 3), with residual pitted scars as documented histologically in a biopsy obtained from to same area (Figure 4). The treatment was continued for six months and then tapered, but a new worsening was observed. Therefore the therapy was resumed and stopped after five months due to drug-hepatotoxicity, with early relapse of skin lesions and progressive destruction of nose's cartilage.

Cutaneous involvement is common in AtaxiaTelangectasia and usually it presents with cutaneous telangiectasia, skin atrophy, café-au-lait spots and premature graying. Cutaneous granulomas have occasionally been reported in patients with A-T [3-11], whereas acne rosacea has not been previously described in patients with A-T.

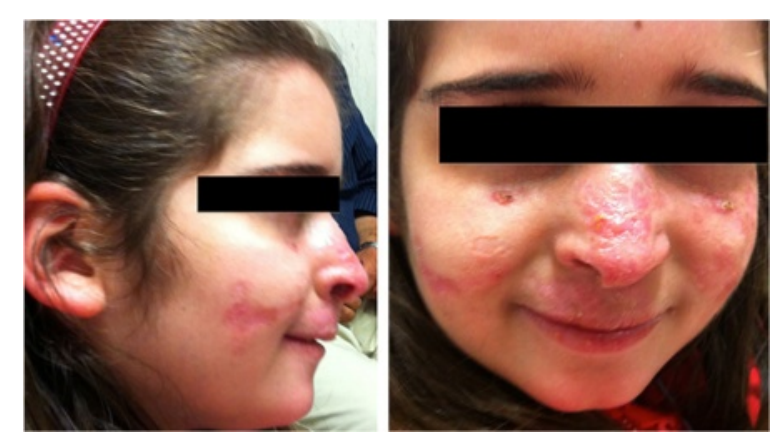

Figure 3 Picture of the patient after five months of systemic treatment with Isotretinoin $(0,5 \mathrm{mg} / \mathrm{kg} / \mathrm{die})$ : the erythematous, papular-nodular and ulceronectrotic lesions disappeared with some residual pitted scars.
Acne rosacea is a chronic inflammatory disorder, characterized by centrofacial erythema, telangiectasias, papules, pustule and occasionally nodules or cysts on the forehead, cheek and nose. Rosacea can be classified in four different subtypes: erythemato-teleangiectatic, papulopustular, phymatous and ocular [12].

Cutaneous manifestations in immunocompromised patients have usually an atypical onset with chronic evolution and require more aggressive and prolonged therapy than non-immunocompromised one.

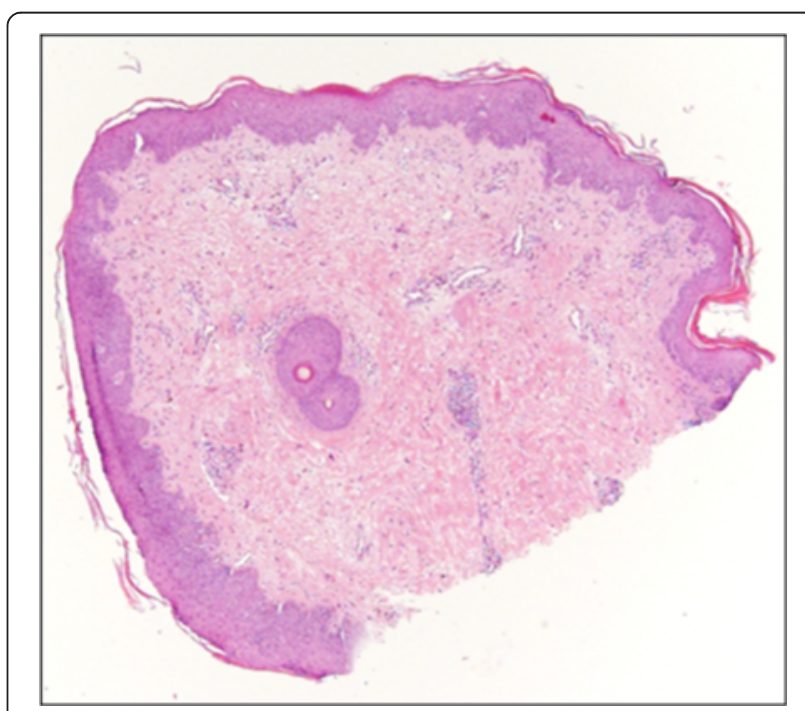

Figure 4 Post-isotretinoin skin biopsy showing mild changes: slight hyperkeratosis, focal parakeratosis, acanthosis. The dermis shows thickened collagen bundles, telangectasias and sparse or periadnexal lymphocytes. HE $4 \mathrm{x}$. 
IVIG was reported to induce regression of the lesions in some patients with PIDs; other have described the development and persistence of cutaneous granulomas in patients on intravenous immunoglobulin replacement therapy [2,3]. Similarly, topic and systemic steroids in conjunction with antibiotics had no effects. Noteworthy, the cutaneous disease control in some PID's patients has been obtained only after hematopoietic stem cells transplantation [2].

The conventional therapeutic regimens for acne rosacea, in non-immunocompromised patients, include topical and oral metronidazol, topical azelaid acid and oral doxycycline, in addition to adequate skin care [13]. Further interesting therapy option could be Isotretinoin, used off-label because of the lack of evidence-based data [14].

Isotretinoin is a synthetic retinoid derived from retinol, that is primary use orally for the treatment of severe, refractory, inflammatory acne. In literature is reported the efficacy of Isotretionin treatment, in patient affected by acne rosacea, at the dosage of $0.5 \mathrm{mg} / \mathrm{kg} / \mathrm{day}$. In particular its use is indicated for those patients who had experienced insufficient or transient effects with conventional topical and systemic therapies. The efficacy of Isotretinoin in rosacea is probably related to its anti-inflammatory, antioxidative, antiangiogenic, and antifibrotic properties, in addition to its ability to reduce the size of sebaceous glands [15].

Our patient is immunocompromised, she received multiple oral and topical treatments (steroids, mupirocin, metronidazole, tetracycline, clindamycin and pimecrolimus), without any improvement, whereas the lesions disappeared after five months of Isotretinoin, with residual pitted scars. In spite of its anti-inflammatory and immunomodulator properties, we did not observe an impairment of immune responses in our child, but on the other side a severe hepatotoxicity was detected and the treatment was stopped.

\section{Conclusion}

Due to our experience, the choice of Isotretinoin should be carefully considered in patients with A-T for the treatment of acne rosacea resistant to conventional therapies, however its toxicity may limit long-term use and the risk/benefit ratio of the treatment should be evaluated.

\section{Consent}

Written informed consent was obtained from the parents of the patient for publication of this Case report and any accompanying images. A copy of the written consent is available for review by the Editor-in-Chief of this journal.

\section{Abbreviations}

A-T: Ataxia-Telangiectasia; ATM: Ataxia-Telangiectasia mutated; IVIG: Intravenous immunoglobulin replacement therapy; PIDs: Primary immunodeficiencies.

\section{Competing interests}

The authors declare that they have no competing interests.

\section{Authors' contributions}

NC and AC were involved in clinical care of patient and drafted the paper. GA were involved in clinical care and in the collection of clinical data of the patient. LC carried out the Western Blot analysis. FC carried out the histological studies. MEH and AD participated in the clinical and therapeutic care of the patient and reviewed the manuscript. AF defined the clinical picture of the patient, formulated diagnosis and critically reviewed the paper. All authors have read and approved the final manuscript.

\section{Acknowledgements}

We want to thank the patient and her family for their active collaboration and participation.

\section{Author details}

'Department of Systems Medicine, University of Rome "Tor Vergata", Unit of Immunology and Infectious Disease, "Bambino Gesù" Children's Hospital, Via Montpellier 1, 00133 Rome, Italy. 'Department of Clinical Molecular Medicine, University "La Sapienza", Rome, Italy. ${ }^{3}$ Department of Pathology, Bambino Gesù Children Hospital, IRCCS, Rome, Italy. ${ }^{4}$ Department of Pediatrics, Unit of Dermatology, Bambino Gesù Children Hospital, IRCCS, Rome, Italy.

Received: 10 December 2014 Accepted: 10 March 2015

Published online: 28 March 2015

\section{References}

1. Cohen LE, Tanner DJ, Schaefer HG, Levis WR. Common and uncommon cutaneous finding in patients with ataxia telangiectasia. J Am Acad Dermatol. 1984;10:431-8.

2. Chiam LY, Verhagen MM, Haraldsson A, Wulffraat N, Driessen GJ, Netea MG, et al. Cutaneous granulomas in ataxia telangiectasia and other primary immunodeficiencies: reflection of inappropriate immune regulation? Dermatology. 2011;223(1):13-9.

3. Mitra A, Pollock B, Gooi J, Darling JC, Boon A, Newton-Bishop JA. Cutaneous granulomas associated with primary immunodeficiency disorders. $\mathrm{Br} J$ Dermatol. 2005;153(1):194-9.

4. Fleck RM, Myers LK, Wasserman RL, Tigelaar RE, Freeman RG. Ataxia-telangiectasia associated with sarcoidosis. Pediatr Dermatol. 1986;3(4):339-43.

5. Paller AS, Massey RB, Curtis MA, Pelachyk JM, Dombrowski HC, Leickly FE, et al. Cutaneous granulomatous lesions in patients with ataxia-telangiectasia. J Pediatr. 1991;119(6):917-22.

6. Joshi RK, al Asiri RH, Haleem A, Abanmi A, Patel CK. Cutaneous granuloma with ataxia telangiectasia-a case report and review of literature. Clin Exp Dermatol. 1993;18(5):458-61.

7. Drolet BA, Drolet B, Zvulunov A, Jacobsen R, Troy J, Esterly NB. Cutaneous granulomas as a presenting sign in ataxia-telangiectasia. Dermatology. 1997;194(3):273-5.

8. Murakawa GJ, McCalmot T, Frieden IJ. Chronic plaques in a patient with ataxia telangiectasia. Cutaneous granulomatous lesions in a patient with AT. Arch Dermatol. 1998;134(9):1145. 1148.

9. Sentürk N, Hindioğlu U, Sahin S, Gököz A. Granulomatous skin lesions in a patient with ataxia telangiectasia. Br J Dermatol. 1998;139(3):543-4.

10. Corbisier A, Eschard C, Motte J, Munzer M, Barhoum K, Kalis B, et al. Cutaneous granulomatous lesions disclosing ataxia-telangiectasia. Ann Dermatol Venereol. 1999;126(8-9):608-11.

11. Folgori $L$, Scarselli A, Angelino G, Ferrari F, Antoccia A, Chessa L, et al. Cutaneous granulomatosis and combined immunodeficiency revealing Ataxia-Telangiectasia: a case report. Ital J Pediatr. 2010;36:29. doi:10.1186/ 1824-7288-36-29.

12. Park H, Del Rosso JQ. Use of oral isotretinoin in the management of rosacea. J Clin Aesthet Dermatol. 2011;4(9):54-61. 
13. Korting HC, Schöllmann C. Current topical and systemic approaches to treatment of rosacea. J Eur Acad Dermatol Venereol. 2009;23(8):876-82.

14. Gollnick H, Blume-Peytavi U, Szabó EL, Meyer KG, Hauptmann P, Popp G, et al. Systemic isotretinoin in the treatment of rosacea -doxycycline- and placebo-controlled, randomized clinical study. J Dtsch Dermatol Ges. 2010;8(7):505-15.

15. Rallis $\mathrm{E}$, Korfitis C. Isotretinoin for the treatment of granulomatous rosacea: case report and review of the literature. J Cutan Med Surg. 2012;16(6):438-41.

Submit your next manuscript to BioMed Central and take full advantage of:

- Convenient online submission

- Thorough peer review

- No space constraints or color figure charges

- Immediate publication on acceptance

- Inclusion in PubMed, CAS, Scopus and Google Scholar

- Research which is freely available for redistribution 